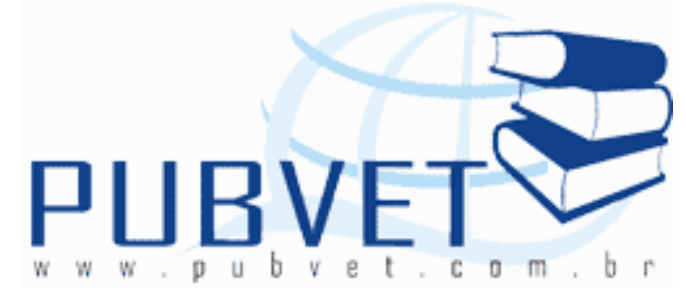

PUBVET, Publicações em Medicina Veterinária e Zootecnia.

\title{
Desafios e oportunidades da identificação eletrônica em suínos
}

\section{Matheus Dhein Dill ${ }^{1}$ e João Garibaldi Almeida Viana ${ }^{2}$}

1 Médico Veterinário, Mestre e Doutorando em Agronegócios. Universidade Federal do Rio Grande do Sul. Programa de Pós-Graduação em Agronegócios.

2 Zootecnista, Mestre em Extensão Rural, Doutor em Agronegócios. Professor Adjunto da Universidade Federal do Pampa.

\section{Resumo}

A demanda por produtos seguros está em amplo crescimento no mercado mundial. A implementação da rastreabilidade em suínos poderá fornecer benefícios para produtores, indústrias e consumidores. $\mathrm{O}$ objetivo do presente trabalho foi conceituar e analisar os meios de identificação utilizados no processo da rastreabilidade suína no Brasil, bem como descrever os novos identificadores eletrônicos encontrados no mercado. Utilizou-se da pesquisa bibliográfica para conceituar rastreabilidade e descrever os métodos de identificação aplicados na suinocultura. Os identificadores atualmente utilizados na cadeia produtiva suína apresentam baixo nível tecnológico e baixa confiabilidade, devido a erros na coleta e processamento de dados. No mercado existem diversos identificadores eletrônicos, mas ainda não estão sendo utilizados devido aos elevados custos e a falta de incentivos pelos participantes da cadeia. Com a utilização de identificadores eletrônicos na rastreabilidade suína, o processo de gestão da informação será maximizado, que possibilitará maior agilidade e confiança nas trocas de informações, 
proporcionando ferramentas que aumentaram a eficiência e eficácia de todos os participantes. O nível tecnológico dos produtores rurais e a falta de incentivos dos órgãos públicos e privados são os principais desafios para o estabelecimento da rastreabilidade eletrônica.

Palavras-chave: cadeia produtiva; identificação eletrônica; carne.

\title{
Challenges and opportunities of electronic identification in pigs
}

\begin{abstract}
The demand for safe products is in growth in the world market. The implementation of traceability in swine may provide benefits to producers, industries and consumers. The objective of this work was to conceive and examine the means of identification used in the process of swine traceability of Brazil, and describe the new electronic identifiers found on the market. It was used the literature search for conceive traceability and describe the methods of identification used in swine production. The identifiers currently used in swine production chain have low technological level and low reliability due to errors in collecting and processing data. In the market there are several electronic identifiers, but are not yet being used due to high costs and lack of incentives by participants in the chain. With the use of electronic identifiers in swine traceability, the process of managing information will be maximized, which will enable greater agility and confidence in the exchange of information, providing tools that increased the efficiency and effectiveness of all participants. The technological level of rural producers and lack of incentives for public and private organizations are the main challenges for the establishment of electronic traceability.
\end{abstract}

Keywords: supply chain; electronic identification; meat.

\section{Introdução}

A carne suína é a principal fonte de proteína animal consumida no mundo. O setor suinícola possui importância social através da geração de 
DILL, M.D. e VIANA, J.G.A. Desafios e oportunidades da identificação eletrônica em suínos. PUBVET, Londrina, V. 6, N. 34, Ed. 221, Art. 1467, 2012.

empregos e renda, contribuindo para o crescimento do produto interno bruto (PIB) do agronegócio no Brasil (SOUZA et al., 2011).

Devido ao grande crescimento da demanda do mercado consumidor nacional e internacional por produtos rastreados, urge o desenvolvimento de conhecimentos sobre processos de identificação e rastreamento de informações na produção animal (SILVA et al., 2004).

A suinocultura tornou-se uma atividade de alta competitividade tanto no Brasil como no exterior. Para que o suinocultor possa manter-se no mercado, ou ainda, aumentar a produção a baixo custo, com qualidade e competitividade, é essencial um constante trabalho de modernização, adaptação e melhoria de todos os setores desta cadeia produtiva (LEITE et al., 2000).

A demanda por produtos limpos, saudáveis e seguros está em amplo crescimento no mercado mundial, principalmente por alimentos de origem animal. Assim, surge á necessidade do estabelecimento de instrumentos tecnológicos que auxiliem na gestão de produção, fiscalização, coleta de dados zootécnicos do nascimento até o abate para a obtenção de qualidade, inocuidade alimentar, eficiência e eficácia na produção.

A rastreabilidade é o primeiro passo para atender as novas demandas dos consumidores do mundo, que se tornam cada vez mais exigentes quanto à qualidade e à inocuidade dos alimentos. O produtor precisa da rastreabilidade como ferramenta de gestão, de captação e registro de dados zootécnicos e de manejo. Empresas comerciais desejam a identificação para que possam oferecer aos clientes produtos de qualidade e de origem conhecida. Finalmente, o consumidor tende a exigir o conhecimento sobre a origem da carne que consome (SILVA et al., 2004).

A implementação da rastreabilidade em suínos poderá fornecer dados confiáveis, com maior facilidade e rapidez das informações, permitindo maior eficiência na troca de informação nos diferentes setores da cadeia produtiva. A cadeia suinícola é altamente competitiva, ou seja, as mudanças tecnológicas 
são almejadas e rapidamente aplicadas a fim de se obter benefícios com a liderança em custos ou rentabilidade através da diferenciação de produtos.

A rastreabilidade pode proporcionar ao produtor rural o processamento de forma rápida e eficiente dos dados zootécnicos de seu plantel, gerando ferramentas estratégicas de controle, além de proporcionar à indústria a diminuição dos riscos de informações assimétricas, estabelecendo maior relação com os produtores e fornecendo maior segurança aos seus clientes. Desta forma, estudar as possíveis formas de rastreabilidade na suinocultura trará elementos importantes para futuras intervenções que objetivem produzir produtos de qualidade, seguros e competitivos no mercado mundial.

O presente trabalho teve como objetivo conceituar e analisar os meios de identificação utilizados no processo da rastreabilidade suína do Brasil, bem como descrever os novos identificadores eletrônicos encontrados no mercado.

\section{Material e métodos}

O trabalho buscou relacionar a rastreabilidade com a identificação eletrônica como ferramenta para o desenvolvimento de novos sistemas informatizados para a melhora da gestão da informação na suinocultura.

Para conceituar rastreabilidade, descrever os métodos de identificação aplicados na suinocultura brasileira e apontar os principais meios de identificação eletrônica utilizou-se da pesquisa bibliográfica.

A pesquisa bibliográfica, segundo Cervo et al., (2007) procura explicar um problema a partir de referências teóricas publicadas, buscando conhecer e analisar as contribuições científicas sobre determinado problema. 0 procedimento seguiu as etapas propostas por Lakatos e Marconi (1986): identificação, localização, compilação, fichamento, análise e interpretação. Documentos bibliográficos secundários sobre rastreabilidade foram acessados. Informações relativas aos métodos de identificação suinícola foram extraídos e estruturados para uma análise a partir de seus benefícios e limitações.

A análise dos resultados, neste trabalho, foi segmentada, a partir de Lakatos e Marconi (1986), em três níveis: Interpretação (verificação das 
DILL, M.D. e VIANA, J.G.A. Desafios e oportunidades da identificação eletrônica em suínos. PUBVET, Londrina, V. 6, N. 34, Ed. 221, Art. 1467, 2012.

relações entre os métodos de identificação suinícola, bem como as vantagens e desvantagens de cada método); Explicação (esclarecimento sobre os conceitos e aplicações da rastreabilidade) e Especificação (argumentação sobre entraves da rastreabilidade e desafios para sua aplicação).

As principais informações sobre métodos de identificação na rastreabilidade suína foram estruturadas em tabelas para melhor visualização comparativa e descrição conceitual, bem como servir para o uso em futuras pesquisas.

\section{Resultados e discussão}

A rastreabilidade surgiu nos Estados Unidos dentro da gestão da qualidade das linhas de montagem da indústria aeroespacial. Pelos padrões internacionais rastreabilidade é a capacidade de recuperação do histórico, da aplicação ou da localização de uma entidade (ou item) por meio de identificações registradas (HOFF, 2007).

A rastreabilidade é caracterizada como um processo de verificação e registro de todas as atividades pertinentes para a produção de um bem (VIANA et al., 2011). Este processo está incluso em toda a cadeia produtiva, desde os fornecedores de insumos, transporte, armazenamento, controle, meio ambiente, produção, embalagem, distribuição, ou seja, de montante à jusante. Wilson e Clarke (1998) relatam que além destas informações descritas anteriormente, a rastreabilidade deve introduzir em suas operações de informações aspectos relevantes sobre impactos ambientais e sociais.

A rastreabilidade é estabelecida para identificar os meios utilizados em todo sistema de produção de um determinado produto. Conforme Prall (2002), um sistema de rastreabilidade contém elementos de identificação de animais e localidade, um banco de dados central e um processo de verificação. Assim, dados como data de nascimento do animal, origem, raça, data de abate, informações sobre manejos, normas ambientais e métodos de bem estar animal são fatores relevantes identificados para a indústria, produtor, consumidor e organizações (MAYRINK, 2002). 
Associada a rastreabilidade está a transparência, a qual se refere a disponibilidade de informações de todos os procedimentos, regras e práticas usadas para produzir um alimento em cada nível da cadeia produtiva. Contudo, para que a rastreabilidade seja completa, é necessária a identificação de todos os insumos secundários, tais como produtos utilizados na formulação de rações, medicamentos utilizados nos animais, linhagem genética (TALAMINI, 2003).

Cabe ressaltar que a identificação não pode ser confundida com a rastreabilidade. A identificação é um dos meios para desenvolver a implantação do processo de rastreabilidade. Atualmente os materiais utilizados na identificação suína no processo de rastreabilidade são as tatuagens, brincos plásticos e mossagem auricular. Estes métodos empregados possuem dificuldades e entraves, conforme descritos na Tabela 1.

Tabela 1 - Métodos de identificação utilizados na suinocultura do Brasil

\begin{tabular}{|c|c|}
\hline Identificadores & Limitações ao uso \\
\hline Tatuagem & $\begin{array}{l}\text { Possibilidade de apagar com o tempo; } \\
\text { Difícil visualização. }\end{array}$ \\
\hline Brincos plásticos & $\begin{array}{l}\text { Possibilidade de cair ou serem retirados por outros animais; } \\
\text { Possibilidade de erro de leitura; } \\
\text { Fixação de impurezas no código de barra/números pode } \\
\text { dificultar ou inviabilizar a leitura. }\end{array}$ \\
\hline Mossagem auricular & $\begin{array}{l}\text { Processo doloroso e de difícil aplicação; } \\
\text { Novas normas de bem estar animal podem impedir este } \\
\text { procedimento. }\end{array}$ \\
\hline
\end{tabular}

Evidencia-se a importância do conhecimento de novos meios para suprir a deficiência dos atuais métodos utilizados. Desta forma, as alternativas encontradas é o uso de identificadores eletrônicos como: brincos, anéis e colares; transponder injetável; sistema biométrico de identificação e análises laboratoriais. As características de cada método eletrônico, bem como seus benefícios e limitações no uso da rastreabilidade suína são discutidos na Tabela 2. 
DILL, M.D. e VIANA, J.G.A. Desafios e oportunidades da identificação eletrônica em suínos. PUBVET, Londrina, V. 6, N. 34, Ed. 221, Art. 1467, 2012.

Tabela 2 - Identificadores eletrônicos e suas características, vantagens e desvantagens.

\begin{tabular}{|c|c|c|c|}
\hline $\begin{array}{l}\text { Identificador } \\
\text { es }\end{array}$ & Característica & Vantagens & Desvantagens \\
\hline $\begin{array}{l}\text { Brincos, Anéis } \\
\text { e colares }\end{array}$ & $\begin{array}{l}\text { Transponder/ } \\
\text { microchip } \\
\text { acoplado no seu } \\
\text { interior. }\end{array}$ & $\begin{array}{l}\text { - Rápida e fácil leitura; } \\
\text { - Custo baixo; } \\
\text { - Durante o abate são } \\
\text { retirados com facilidade; } \\
\text { - Baixo risco a segurança } \\
\text { dos alimentadores. }\end{array}$ & $\begin{array}{l}\text { - Os brincos anéis ou } \\
\text { colares podem cair e } \\
\text { perder as informações } \\
\text { coletadas. } \\
\text { - Outros animais do lote } \\
\text { muitas vezes arrancam. }\end{array}$ \\
\hline $\begin{array}{l}\text { Transponder } \\
\text { Injetável }\end{array}$ & $\begin{array}{l}\text { - Possui } \\
\text { mesmas as } \\
\text { características de } \\
\text { recepção } \\
\text { dados que } \\
\text { brincos, anéis e } \\
\text { colares. }\end{array}$ & $\begin{array}{l}\text { - Aplicação via subcutânea } \\
\text { fácil, rápida e pouco } \\
\text { dolorosa; } \\
\text { - Não provoca reação no } \\
\text { organismo animal; } \\
\text { - Acompanha o suíno } \\
\text { durante toda sua vida. }\end{array}$ & $\begin{array}{l}\text { - Possível migração do } \\
\text { transponder no animal; } \\
\text { - Dificuldades na retirada } \\
\text { durante o abate, trazendo } \\
\text { problemas na segurança } \\
\text { alimentar; } \\
\text { - Custo elevado. }\end{array}$ \\
\hline $\begin{array}{l}\text { Sistema } \\
\text { Biométrico }\end{array}$ & $\begin{array}{l}\text { - Leitura de } \\
\text { dados através da } \\
\text { imagem da retina } \\
\text { animal. }\end{array}$ & $\begin{array}{l}\text { - A retina mantém suas } \\
\text { características intactas por } \\
\text { toda vida; } \\
\text { - Minimiza os riscos de } \\
\text { fraudes. }\end{array}$ & $\begin{array}{l}\text { - Tempo elevado para a } \\
\text { obtenção da leitura da } \\
\text { retina do animal; } \\
\text { - Necessidade de dominar } \\
\text { o animal frequentemente. }\end{array}$ \\
\hline $\begin{array}{l}\text { Análises } \\
\text { Laboratoriais }\end{array}$ & 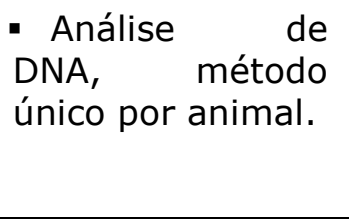 & $\begin{array}{l}\text { - Método não invasivo; } \\
\text { - Identificação até o } \\
\text { consumidor sem utilização } \\
\text { de qualquer material; } \\
\text { - À prova de fraude. }\end{array}$ & $\begin{array}{l}\text { - Alto custo; } \\
\text { - Identificação do animal } \\
\text { não é realizada em tempo } \\
\text { real. }\end{array}$ \\
\hline
\end{tabular}

Fonte: Adaptado de Eradus e Jansen (1999); Prall (2002).

A rastreabilidade utilizada no Brasil ainda é realizada com pouca informatização, os identificadores utilizados são brincos plásticos, tatuagens e cortes de ponta de orelha com custos significativamente mais baixo que os identificadores eletrônicos. Os dados são coletados manualmente e apresentam baixa confiabilidade apresentado dificuldades nas trocas de informações.

A partir da utilização do sistema eletrônico é possível fornecer dados confiáveis, com maior facilidade e rapidez das informações, permitindo maior eficiência na troca de informação nos diferentes setores da cadeia produtiva. A identificação eletrônica minimiza os erros de coleta informações, mas ela deve estar interligada com uma central de armazenagem e processamento de dados, permitindo a perfeita troca de informações dos elos (MACHADO e NANTES, 2004). 
Estas tecnologias têm como objetivo automatizar as granjas, certificar a procedência, industrialização, transporte e comercialização, possibilitando uma perfeita correlação entre produto final e a matéria prima que the deu origem (MACHADO e NANTES, 2004).

Keen (1996) relata que a tecnologia da informação é a soma dos computadores com as telecomunicações e os recursos disponíveis para a captação dos dados pertinentes, e ela só faz sentido quando vista como uma ferramenta para que as empresas transformem a mudança como uma aliada, e não como uma ameaça. Ainda ressalta que as mudanças trazem riscos e oportunidades, e a implementação do sistema dependerá de análises prévias, as quais verificaram a urgência e viabilidade de sua introdução.

Neste contexto a rastreabilidade eletrônica, no futuro, não será mais vista como um diferencial, e sim como uma exigência. Isto fica evidente ao observar as metas da União Européia, considerada uma das principais importadoras de carne suína brasileira, a qual pretende controlar da melhor forma possível as doenças dos animais, com base no lema de sua campanha "Mais vale prevenir do que remediar" como missão para os anos de 2007 á 2013. Para a União Européia, a rastreabilidade eletrônica tem a finalidade de aumentar a qualidade, exatidão e rapidez perante a obtenção de todos os dados referentes aos animais, assim como a origem dos mesmos e as alimentações utilizadas no processo de produção (COMISSÃO EUROPÉIA, 2007).

Os resultados esperados pela União Européia, referentes á rastreabilidade são:

a) Portal único para todos os assuntos do foro veterinário interoperacional das bases de dados de identificação nacionais;

b) Introdução de procedimentos eletrônicos (a mais longo prazo);

c) Estudo de viabilidade para a introdução da identificação eletrônica (com especial atenção para os ruminantes) numa base voluntária ou obrigatória; 
d) Substituição da certificação em papel pela certificação eletrônica nas deslocações de animais vivos (comércio intracomunitário e importações);

e) Criação de um sistema eletrônico integrado mais vasto, com uma base de dados unificada que inclua todos os elementos do atual sistema de certificação, identificação dos animais, estatuto em matéria de saúde e de bem-estar dos animais (COMISSÃO EUROPEIA, 2007).

Pode-se observar que as exigências são voltadas principalmente para ruminantes, mas a cadeia de suinocultura brasileira não pode deixar acontecer desastres para tomar as devidas providências. As ferramentas para a rastreabilidade eletrônica existem e estão à disposição, entretanto o principal entrave para a implementação de um sistema eletrônico na suinocultura brasileira é a falta de incentivos governamentais e o baixo estímulo por parte da indústria no desenvolvimento de softwares para a implementação de um sistema informatizado de gerenciamento (SIG) eficiente nas propriedades rurais.

Projetos integrados entre produtores e indústria devem ser desenvolvidos para estimular o acesso dos suinocultores aos meios digitais e a aplicação gradual da rastreabilidade eletrônica no setor produtivo, a fim de que no longo prazo, tanto produtores como a indústria, estejam aptos a utilizar está ferramenta de forma eficiente e correta.

\section{Conclusões}

A rastreabilidade é de suma importância para todos os atores integrantes da cadeia agroindustrial suína. As tecnologias estão á disposição para a implementação de um sistema eletrônico e informatizado. O grande desafio para a rastreabilidade suína é o estimulo e desenvolvimento de ações conjuntas para sua introdução. Com a entrada deste novo sistema a gestão dos integrantes será otimizada, proporcionando uma rápida e eficiente troca de informação, melhorando o desempenho de todo o setor.

Há dificuldade e fatores limitantes a sua introdução. O principal entrave é o elevado custo para a aplicação e monitoramento. Futuras pesquisas devem 
DILL, M.D. e VIANA, J.G.A. Desafios e oportunidades da identificação eletrônica em suínos. PUBVET, Londrina, V. 6, N. 34, Ed. 221, Art. 1467, 2012.

dar maior atenção à viabilidade econômica da rastreabilidade para que esta nova ferramenta melhore a eficiência de todo o setor, absorvendo seus custos. A competitividade mundial está cada vez mais acirrada e a suinocultura brasileira deve estar constantemente inovando para manter e conquistar novos mercados.

\section{Referências}

CERVO, A. L. et al. Metodologia científica. São Paulo: Pearson Prentice Hall. p. 120-160, 2007.

COMISSÃO EUROPEIA. Uma nova Estratégia de Saúde Animal da União Europeia (20072013) sob o lema "Mais vale prevenir do que remediar". Luxemburgo: Publicações Oficiais das Comunidades Europeias. p. 1-27, 2007.

ERADUS, W. J. e JANSEN, M. B. Animal identification and monitoring. Computers and Electronics in Agriculture, v. 24, n.1, p. 91-98, 1999.

HOFF, E. O que eu ganho com essa tal "rastreabilidade"? p. 1-6, 2007. Acesso em: 16 mai. 2011. Disponível em: http://www.agriness.com/blogdobisteca/?p=47

KENN, P. G. W. Guia Gerencial para a tecnologia da Informação: conceitos essenciais e terminologia para empresas e gerentes. Rio de Janeiro: Campus: p. 16-19. 1996.

LAKATOS, E. M. e MARCONI, M. A. Fundamentos de metodologia científica. São Paulo: Editora Atlas, p. 130-203, 1986.

LEITE, D. M. G. et al. Software para gerenciamento de granjas suinícolas. In: Congresso e mostra de agroinformática, 1., 2000. Anais... UEPG: Ponta Grossa. p. 1-11, 2000. Acesso em: 16 mai. 2011. Disponível em: http://200.201.9.33/artigos/pdf/info 065.pdf

MACHADO, J. G. C. F. e NANTES, J. F. D. A rastreabilidade na cadeia de carne bovina. In: Congresso luso-brasileiro de tecnologia de informação e comunicação na agropecuária, 1., 2004, Santarém. Anais... SBI-AGRO: Santarém. p. 1-14, 2004.

MAYRINK, J. M. Criador quer discutir mais a rastreabilidade. O Estado de São Paulo. São Paulo, 08 de maio, p. 6, 2002.

PRALL, G. Rastreabilidade suína: avanços tecnológicos. In: Seminário internacional sobre produção, mercado e qualidade da carne de suínos, 1., 2002. Anais... EMBRAPA: Florianópolis. p. 1-16, 2002.

SILVA, K. O.; et al. Comparação do uso de rastreabilidade para suínos em grupo e individual. Brazilian Journal of Veterinary Research and Animal Science, v. 41, n.5, p. 327-331, 2004.

SOUZA, R. A.; et al. As tendências de mercado da carne suína. Pubvet, v. 5, n. 25, 2011.

TALAMINI, E. Implementação de programas de segurança alimentar e o uso da ICT pela cadeia exportadora de carne suína brasileira. Dissertação de Mestrado (Programa de Pós-Graduação em Agronegócios). UFRGS: Porto Alegre, 2003. 175p. 
VIANA, J.G.A.; et al. Percepção dos produtores frente à rastreabilidade bovina: estudo comparativo entre Brasil e Chile. Archivos de Zootecnia, v.60, n.231, pp. 825-828. 2011.

WILSON, T.P. e CLARKE, W.R. Food safety and trancebility in the agricultural supply chain: using the Internet to deliver trancebility. Supply Chain Management, v.3, n.3, pp: 126-133. 1998. 